\title{
MEDICAL TATTOOS IMPACT ON CPR DECISIONS
}

\author{
Anna Abelsson \\ Department of Health Sciences, Karlstad University, Sweden
}

Disaster Emerg Med J 2017; 2(3): 140-141

\section{Dear Editor,}

This paper presents the idea of medical directives expressed in the form of tattoos and how care actions performed by medical personnel in both preand in-hospital settings can be put in difficult ethical situations.

Tattoos have increased in popularity, and we are now starting to see tattoos expressing different kinds of personal medical directives. Words such as "No Cardio Pulmonary Resuscitation" or "No CPR" and "Do Not Resuscitate" or "DNR" are examples of what we could find on a patient' sternum. How do we handle these directives and are they legal? Do we obey a patient's wish not to receive CPR? Death is a part of life and is both physiological and biological. Although death is a passage which everyone is confronted with, how the passage takes place is dependent on how the next of kin and the medical personnel respects and regards death [1]. To show compliance with the patient's integrity is important in all health care [2]. To understand the situation the patient is in, involves seeing the patient as a human being and to respect everyone's own free will [3-4]. It is the core of ethics that reveals itself in the medical practitioner's will to protect and comply with the patients' free will [5]. At the same time, how far can we take the right of free will when it comes to medical directives in the form of tattoos?

All medical personnel are trained at different levels of emergency care, most often including CPR. The skills needed to conduct CPR are taught based on the theoretical and medical knowledge that together comprises a successful CPR. When medical personnel are faced with the situation of performing CPR on a person who, for some reason, has suffered a cardiac arrest, there will be more influencing factors present than one's medical knowledge and

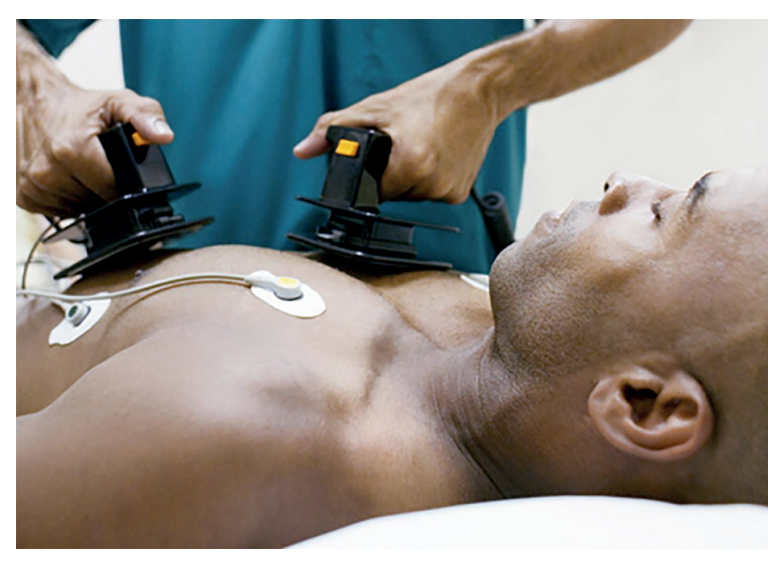

FIGURE 1. Manual defibrillation during CPR.

practical skills. CPR is never conducted in a vacuum, but always in a context of the patient, the relatives, other medical personnel and perhaps, spectators (Fig. 1).

It is usually only terminal or palliative patients who are given the directive "Do Not Resuscitate". Thus, even though we cannot legitimately accept a "No CPR" tattoo, it should always initiate thought on the subject. Are there actually valid directives for not giving CPR? Perhaps relatives can help provide us with documentation. Unless there is evidence of rejecting resuscitation, a tattoo might be an artistic expression that suddenly became a serious message, or a former wish that no longer exists with the person. A person with a cardiac arrest does not have the ability to renounce treatment via a tattoo. Only a conscious person is entitled to say no to medical treatment. Therefore, we need to have discussions on how integrity and self-determination versus treatment guidelines should govern care activities, in the form of CPR, for people with 
medical tattoos. Medical tattoos may become an ethical dilemma in the decision-making process regarding cardiopulmonary resuscitation.

Conflict of interest: None declared.

\section{REFERENCES}

1. Benner P, Kerchner S, Corless IB, et al. Attending death as a human passage: core nursing principles for end-of-life care. Am J Crit Care. 2003; 12(6): 558-561, indexed in Pubmed: 14619363.
2. International Council of Nurses. The ICN code of ethics for nurses. Revised 2012 http://www.icn.ch/images/stories/documents/about/ icncode_english.pdf. Accessed: 2017.06.06.

3. Heijkenskjöld KB, Ekstedt M, Lindwall L. The patient's dignity from the nurse's perspective. Nurs Ethics. 2010; 17(3): 313-324, doi: 10.1177/0969733010361444, indexed in Pubmed: 20444773.

4. Van Der Graaf R, Van Delden JJm. Clarifying appeals to dignity in medical ethics from an historical perspective. Bioethics. 2009; 23(3): 151-160, doi: 10.1111/j.1467-8519.2008.00646.x, indexed in Pubmed: 19161568

5. Eriksson K. Caring Science in a New Key. Nursing Science Quarterly. 2002; 15(1): 61-65, doi: 10.1177/08943180222108642. 